\title{
Effect of starvation on Fos and neuropeptide immunoreactivities in the brain and pituitary gland of Xenopus laevis
}

\author{
M. Calle ${ }^{\text {a,c,**}}$, T. Kozicz ${ }^{\text {a }}$, E. van der Linden ${ }^{\text {a }}$, A. Desfeux ${ }^{\text {d }}$, J.G. Veening ${ }^{\text {, }}$, \\ H.P. Barendregt ${ }^{\mathrm{c}}$, E.W. Roubos ${ }^{\mathrm{a}}$ \\ ${ }^{a}$ Department of Cellular Animal Physiology, Institute for Neuroscience, Radboud University Nijmegen, Nijmegen, The Netherlands \\ ${ }^{\mathrm{b}}$ Department of Anatomy and Embryology, Radboud University Nijmegen, Nijmegen, The Netherlands \\ ${ }^{\mathrm{c}}$ Department of Computational Sciences, Institute for Computing and Information Sciences, Radboud University Nijmegen, The Netherlands \\ ${ }^{\mathrm{d}}$ European Institute of Peptide Research, Cellular and Molecular Neuroendocrinology, IFRMP 23, University of Rouen, Mont-Saint-Aignan, France
}

Received 8 November 2005; revised 3 January 2006; accepted 5 January 2006

\begin{abstract}
In mammals complex interactions between various brain structures and neuropeptides such as corticotropin-releasing factor (CRF) and urocortin 1 (Ucn1) underlay the control of feeding by the brain. Recently, in the amphibian Xenopus laevis, CRF- and Ucn1-immunoreactivities were shown in the hypothalamic magnocellular nucleus $(\mathrm{Mg})$ and evidence was obtained for their involvement in food intake. To gain a better understanding of the brain structures controlling feeding in $X$. laevis, the effects of 16 weeks starvation on neurones immunoreactive (ir) to Fos and neuropeptides in various brain structures were quantified. In the Mg, compared to controls, starved animals showed fewer neurones immunopositive for Fos $(-55.9 \%)$, Ucn1 $(-44.0 \%)$, cocaine and amphetamine-regulated transcript (CART) $(-94.3 \%)$ and metenkephalin (ENK) $(-65.0 \%)$, whereas CRF-ir neurones were 2.1 times more numerous. These differences were mainly apparent in the ventral part of the $\mathrm{Mg}$, followed by the medial and dorsal part of the nucleus. In the neural lobe of the pituitary gland a $22.5 \%$ lower optical density of CART-ir was observed. In the four other brain structures investigated, starvation had different effects. The dorsomedial part of the suprachiasmatic nucleus showed 5.9 times more NPY-ir cells and in the ventromedial thalamic area a lower number of NPY-ir cells $(-33.6 \%)$ was found, whereas the Edinger-Westphal nucleus contained fewer CART-ir cells $(-42.2 \%)$; no effect of starvation was seen in the ventral hypothalamic nucleus. Our results support the hypothesis that in $X$. laevis, the Mg plays a pivotal role in feeding-related processes and, moreover, that starvation also has neuropeptide- and brain structure-specific effects in other parts of the brain and in the pituitary gland, suggesting particular roles of these structures and their neuropeptides in physiological adaptation to starvation.
\end{abstract}

(C) 2006 Elsevier Inc. All rights reserved.

Keywords: Neuropeptides; Feeding; Immunocytochemistry; Fos; CRF; Urocortin 1; CART; NPY; Metenkephalin

\section{Introduction}

Corticotropin-releasing factor $(\mathrm{CRF})$ is a 41 amino acid neuropeptide that in mammals controls a wide range of physiological responses to physical and emotional stressors (e.g., Tsigos and Chrousos, 2002; Vale et al., 1981), including neuroendocrine and behavioral

\footnotetext{
${ }^{*}$ Corresponding author. Fax: +31243652714 .

E-mail address: m.calle@science.ru.nl (M. Calle).
}

responses, inflammatory responses to immunological agents, and modulation of gastrointestinal (Baigent and Lowry, 2000) and cardiovascular activity (Parkes et al., 2001). Urocortin 1 (Ucn1) is a 40 amino acid peptide structurally related to CRF. It was discovered in 1995 (Vaughan et al., 1995) and although its physiological significance is less extensively documented than that of CRF, it seems also to be involved in various autonomic and behavioural stress adaptation processes (e.g., Kórösi et al., 2005; Kozicz et al., 2004; Skelton et al., 2000). Recently, roles of CRF and Ucn 1 in the regulation of feeding have 
been suggested because their central administration diminishes food intake (e.g., Heinrichs and Richard, 1999; Jones et al., 1998; Momose et al., 1999; Spina et al., 1996) and counteracts neuropeptide Y (NPY)-induced feeding (Wang et al., 2001).

The profound and widespread physiological actions of CRF and Ucn1 become even more apparent from research on amphibians and, especially, on the aquatic toad Xenopus laevis. CRF and Ucn 1 are present in the amphibian homologue of the supraoptic and paraventricular nucleus in mammals, the magnocellular nucleus $(\mathrm{Mg}$; Calle et al., 2005a; Ubink et al., 1997; Verburg-Van Kemenade et al., 1987). The Mg is activated by acute hyperosmotic challenge (Ubink et al., 1997), suggesting the involvement of CRF and Ucn 1 in the amphibian stress response. Furthermore, both CRF and Ucn1 stimulate the release from the intermediate lobe of the pituitary gland of $\alpha$-melanophore-stimulating hormone, a hormone involved in skin colour adaptation to changed background illumination (Jenks et al., 2002; Roubos, 1997; Roubos et al., 2005; Scheenen et al., 1995). Moreover, central administration of CRF and Ucn 1 suppresses food intake by $X$. laevis in a dose-dependent way (Boorse et al., 2005; Crespi et al., 2004), and the brain content of $X$. laevis CRF mRNA varies with the level of the animal's nutritional state, strongly decreasing upon food deprivation (Crespi et al., 2004). However, the brain structures that control feeding-related processes in $X$. laevis have not been identified, which was the reason to start the present investigation.

Recently, detailed studies were made of the distribution of CRF and Ucn1 in the central nervous system of $X$. laevis. It appeared that both peptides are widespread, indicating that they exert a large variety of actions, but they also show some overlap, mainly in the Mg (Calle et al., 2005a; Yao et al., 2004). Because of this coexistence of both feeding-related neuropeptides, we hypothesize that $\mathrm{CRF}$ and $\mathrm{Ucn} 1$ in the $\mathrm{Mg}$ are involved in the regulation of feeding. Using a long-term (16 weeks) starvation paradigm, we have assessed the degree of activation of the $\mathrm{Mg}$ by studying Fos expression, and the dynamics of CRF and Ucn 1 using immunocytochemistry. To determine if the starvation stimulus would have a feeding-specific rather than a general stressor effect, and would specifically act on the $\mathrm{Mg}$, a number of other neuropeptides and brain structures were studied as well. These peptides comprised factors known to be involved in some way in feeding control in mammals, namely cocaine and amphetamine-regulated transcript (CART; Douglass et al., 1995; Kuhar and Dall, 1999; Vrang et al., 1999), NPY (Stanley and Leibowitz, 1985) and metenkephalin (ENK; Gosnell and Lipton, 1986). In addition to the $\mathrm{Mg}$, we studied the suprachiasmatic nucleus (SC), a main centre of NPY expression in the $X$. laevis brain (Tuinhof et al., 1994), the ventral hypothalamic area $(\mathrm{VH})$, which is homologous with the mammalian arcuate nucleus, a main hypothalamic centre involved in the regulation of food intake
(Johansen et al., 2000), the Edinger-Westphal nucleus, which is the main site of Ucn 1 expression in both amphibians and mammals (Bittencourt et al., 1999; Calle et al., 2005a; Kozicz et al., 1998; Skelton et al., 2000) and is involved in the stress response in mammals (Kórösi et al., 2005; Kozicz et al., 2004), and the ventromedial thalamic nucleus (VM), which served as a negative control as it is not known to play a role in the control of feeding (ten Donkelaar, 1998).

\section{Materials and methods}

\subsection{Animals}

Twenty young adult aged 6 months specimens of $X$. laevis, with a body weight of $32-35 \mathrm{~g}$, were raised under standard laboratory conditions, under constant illumination, at a water temperature of $22 \pm 1{ }^{\circ} \mathrm{C}$, on a grey background, for 16 weeks. Ten control animals were fed weekly on ground beef heart (Janssen, Nijmegen, The Netherlands) and trout pellets (Trouvit, Trouw, Putten, The Netherlands). The other 10 animals did not receive any food. A first group $(n=5)$ was used for the Fos study and a second group $(n=5)$ was used to study effects of starvation on the immunoreactivities against various neuropeptides. Brain sections of control and starved animals were processed in parallel for immunocytochemistry, for each peptide studied. Studies were carried out in accord with the Declaration of Helsinki and the Dutch law concerning animal welfare, as tested by the Committee for Animal Experimentation of Radboud University Nijmegen.

\subsection{Immunocytochemistry}

Toads were deeply anaesthetized by immersion in $0.1 \%$ tricaine methane sulfonate (MS222; Novartis, Basel, Switzerland) in tap water, and transcardially perfused with ice-cold $0.6 \%$ sodium chloride, for $5 \mathrm{~min}$. Then they were perfused with $250 \mathrm{ml}$ ice-cold Bouin's fixative, for $15 \mathrm{~min}$. After decapitation, the brain and pituitary gland were quickly dissected and postfixed in the same fixative, for $16 \mathrm{~h}$ at $4{ }^{\circ} \mathrm{C}$, washed in $70 \%$ ethanol for $24 \mathrm{~h}$, to eliminate excess of picric acid, dehydrated in a graded ethanol series, and embedded in paraffin. Coronal serial sections $(7 \mu \mathrm{m})$ were mounted on poly-L-lysine-coated slides (Sigma, St Louis, MO, USA) and allowed to air-dry, for $16 \mathrm{~h}$ at $45^{\circ} \mathrm{C}$, deparaffinized, rehydrated, and treated for immunocytochemistry, as described before (Calle et al., 2005a). As to the Fos staining, the antigen retrieval method of Shi et al. (1993) was used. After deparaffinization, sections were pre-heated in a microwave oven at $90{ }^{\circ} \mathrm{C}$ in $0.3 \%$ tri-sodium citrate buffer (pH. 6.0), for $10 \mathrm{~min}$. After a $10 \mathrm{~min}$ wash in cold water, immunostaining was performed. In brief, endogenous peroxidase activity was quenched with $0.1 \% \mathrm{H}_{2} \mathrm{O}_{2}$ in sodium phosphate-buffered saline (PBS), for $30 \mathrm{~min}$, after which sections were rinsed twice in PBS, for $15 \mathrm{~min}$. Then they were incubated for $1 \mathrm{~h}$ in PBS containing 0.5\% Triton X-100 (PBST; Sigma), 2.5\% normal goat serum (NGS; Vector Laboratories, Burlingame, CA, USA), and $2.5 \%$ normal horse serum (NHS, Vector Laboratories), treated with avidin/biotin blocking solution (Vector Laboratories), for $15 \mathrm{~min}$, and incubated with the respective primary antisera, diluted in PBST, for $16 \mathrm{~h}$ at $20^{\circ} \mathrm{C}$

The rabbit anti-c-Fos serum (dilution: 1:100) was from Santa Cruz Biotechnology (sc-253, Santa Cruz, CA, USA) and shown to specifically recognize Xenopus Fos protein (Ubink et al., 1997). The highly specific rabbit anti-Xenopus CRF (xCRF; dilution: 1:15) (Boorse and Denver, 2004; Calle et al., 2005a; Yao et al., 2004), rabbit anti-rat Ucn1 (1:30,000) (Bittencourt et al., 1999; Kozicz et al., 2002), rabbit antibovine ENK (1:1000) (Calle et al., 2005b) and rabbit anti-Xenopus NPY (xNPY; 1:8000) (Tuinhof et al., 1994; Ubink et al., 1997) sera had been used in our laboratories before. The C6-1 F4D4 CART-antiserum $(1: 100,000)$ had been raised in mice against the 109-126 fragment of rat CART peptide (Koylu et al., 1997; Lázár et al., 2004). 
Immunodetection was carried out with a Vectastain $\mathrm{ABC}$ elite kit (Vector Laboratories). After rinsing the sections in PBS and in Tris- $\mathrm{HCl}$ buffer for $30 \mathrm{~min}$, the reaction product was visualized with $0.04 \% 3-3^{\prime}-$ diaminobenzidine (DAB; Sigma) and $0.015 \% \mathrm{H}_{2} \mathrm{O}_{2}$ in Tris- $\mathrm{HCl}$ buffer containing $0.5 \%$ nickel-ammonium sulphate. The reaction was terminated by several rinses in Tris- $\mathrm{HCl}$ buffer. Finally, sections were dehydrated in a graded series of ethanol, cleared in xylene, and mounted in Entellan (Merck, Hohenbrunn, Germany).

For all of the sera no immunostaining was seen after preabsorbtion with the respective synthetic peptides $(50 \mu \mathrm{g} / \mathrm{ml})$ for $16 \mathrm{~h}$ at $4{ }^{\circ} \mathrm{C}$. Synthetic ENK peptide was from Bachem (Weil am Rhein, Germany). Omitting primary antisera also abolished immunostaining.

\subsection{Quantification}

For each animal, immunopositive neurones were counted in every tenth section of serial sections of each brain structure, consecutive sections being stained with the respective antisera. Only cell body profiles with a clearly visible nucleus were counted. Per antiserum, counts of the left and the right part of a paired brain structure were summated over all sections of that structure, per animal. For quantifying the density of CART-, Ucn 1-, and ENK-immunoreactivities in the pituitary neural lobe and CRF in the median eminence, images were taken of every tenth section of the lobe or median eminence, with a $20 \times$ objective lens and a Leica DC 500 digital camera mounted on a Leica DMRBE microscope (Leica Microsystems, Heerbrugg, Switzerland). Using Scion Image software (version 3.0b; NIH, Bethesda, MD, USA), specific signal density (SSD) was determined relative to neutral background density present in the unstained intermediate lobe of the pituitary gland (for the neural lobe) or the lateral hypothalamic area (for the median eminence). The diameters of ENK-positive cells in the three sub-areas of the $\mathrm{Mg}$ were measured using a $40 \times$ objective lens and an eyepiece micrometer, over all sections of a sub-area, and averaged per animal.

To check per peptide and per nucleus for a statistically significant effect of starvation on the numbers of immunoreactive cell bodies and on the size of perikarya, data averaged per animal, were tested for homogeneity of variance (Bartlett's test, see Bliss, 1967) and normality (Shapiro and Wilk, 1965), and entered into analysis of variance $(\alpha=5 \%)$, using Statistica (StatSoft, Tulsa, OK, USA).

\section{Results}

\subsection{General observations}

The body weight of control and starved $X$. laevis were measured at the start and at the end of the starvation period. During this period, the mean weight of control animals $(46.7 \pm 2.4)$ had increased by $35.3 \% \quad(P<0.005)$, whereas for starved animals $(29.0 \pm 0.5)$ a clear decrease by $10.9 \%(P<0.005)$ was observed, demonstrating a profound effect of starvation on body growth.

\subsection{Effect of starvation on Fos expression}

In control $X$. laevis, Fos expression was observed in many structures throughout the brain (Fig. 1). In the telencephalon scattered Fos-positive neurones occur in the medial and lateral pallium. The diencephalon shows a high number of such neurones in the SC (Fig. 1A) and moderate numbers in the $\mathrm{VM}$, the $\mathrm{VH}$, and the $\mathrm{Mg}$. In the mesencephalon a moderate number of Fos-positive neurones are present in the torus semicircularis and in the Edinger-Westphal nucleus. In the cerebellum a high number of strongly stained Fos positive neurones were found (Fig. 1B).

The Mg of control animals contained about 30 Fos-positive cells. In the $\mathrm{Mg}$ of starved animals, however, the number of these cells is markedly lower $(-55.9 \% ; P<0.05)$ (Figs. 1C and D). Since three sub-areas in the Mg have been distinguished, viz. the ventral $(\mathrm{MgV})$, the medial $(\mathrm{MgM})$, and the dorsal (MgD) area (Ubink et al., 1997), it is relevant to study these areas with respect to their response to the starvation stimulus. Compared to the controls, in starved animals the number of Fos-ir neurones is much
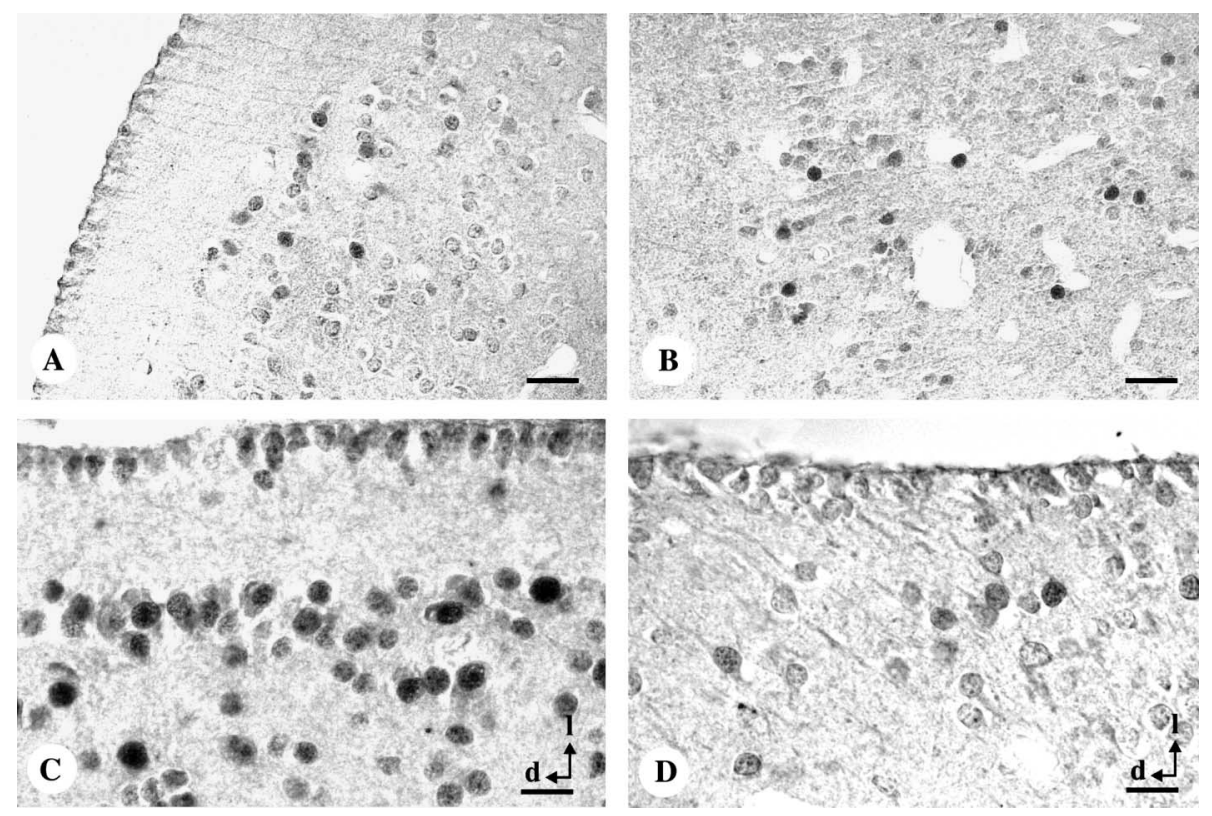

Fig. 1. Neurones in coronal sections of the brain of $X$. laevis, immunoreactive to Fos, in (A) the suprachiasmatic nucleus, (B) the cerebellum and (C) the ventral part of the $\mathrm{Mg}(\mathrm{MgV})$ of a representative control animal, and (D) in the $\mathrm{MgV}$ of a representative starved animal. In C and $\mathrm{D}$, dorsal is not on top and orientation of dorsal (d)-lateral (l) has been indicated. Scale bar $A, B=50 \mu \mathrm{m}, C, D=20 \mu \mathrm{m}$. 
lower in both the $\mathrm{MgV}$ and the $\mathrm{MgM}(-69.4 \%$ and $-52.1 \%$, respectively; $P<0.05$ ) while no effect of starvation is seen in the $\mathrm{MgD}$.

No effect of starvation is statistically demonstrable in any other brain structure quantified $(\mathrm{SC}, \mathrm{VM}, \mathrm{VH}$, and Edinger-Westphal nucleus; Table 1).

\subsection{Effect of starvation on neuropeptides}

In the brain of control $X$. laevis CRF-, Ucn1-, ENK-, NPY-, and CART-ir neurones can be clearly observed, and their distributions are in accord with previous descriptions (CRF and Ucn1: Calle et al., 2005a; ENK: Merchenthaler et al., 1987; NPY: Tuinhof et al., 1994; CART: G. Lázár, M. Calle et al., unpubl. results).

In the $\mathrm{Mg}$, starved animals $(n=5)$ show 2.1 times more CRF-ir neurones than controls $(P<0.005$; Figs. $2 \mathrm{~A}$ and $\mathrm{B})$ whereas the numbers of CART-ir neurones $(-94.3 \%$; $P<0.001$; Figs. $2 \mathrm{C}$ and D), ENK-ir neurones $(-65.0 \%$; $P<0.05$; Figs. $2 \mathrm{E}$ and F) and Ucn1-ir neurones ( $-44.0 \%$; $P<0.05$; Figs. $2 \mathrm{G}$ and $\mathrm{H}$ ) are much lower than in controls. In both control and starved animals only ENK-ir neurones occur in each of the three sub-areas, whereas CRF-, Ucn1-, and CART-ir neurones are only present in the $\mathrm{MgV}$ and MgM (Fig. 2). Compared to controls, in starved animals the peptide antisera reveal the most extensive effects in the $\mathrm{MgV}$, where the number of CRF-ir neurones is 1.6 times higher $(P<0.05)$ and the numbers of Ucn 1-ir $(-44.0 \%$; $P<0.05)$, CART-ir $(-86.1 \% ; P<0.05)$, and ENK-ir neurones $(-72.6 \% ; P<0.05)$ are much lower. In the $\mathrm{MgM}$, starved animals show four times more CRF-ir neurones $(P<0.05)$ and a much lower number of ENK-ir neurones $(-58.2 \% ; P<0.05)$ than controls. Moreover, in the starved animals CART-ir neurones are absent from this part of the $\mathrm{Mg}$ whereas they are numerous in controls $(18.6 \pm 7.6$; $P<0.01)$. In the $\mathrm{MgD}$, starvation only results in a clearly lower number of ENK-ir neurones $(-67.0 \% ; P<0.05)$.

Neurones in the $\mathrm{Mg}$ send axons to the pituitary gland where they form neurohemal axon terminals in the neural lobe. The lobe clearly stains with antisera against Ucn1, ENK, and CART and this staining was measured and expressed as SSD. Starved animals reveal a lower SSD $(-22.5 \% ; P<0.05)$ of CART-ir (Figs. 3A and B) whereas no effect was found for Ucn1- and ENK-ir. Since CRF-ir

Table 1

Quantification of the numbers of cell body profiles immunoreactive to Fos, CRF, Ucn1, CART, ENK, and NPY, in different brain structures of control and starved $X$. laevis, viz. magnocellular nucleus $(\mathrm{Mg})$ and ventral $(\mathrm{MgV})$, medial $(\mathrm{MgM})$ and dorsal $(\mathrm{MgD})$ subareas, suprachiasmatic nucleus $(\mathrm{SC})$ and dorsomedial (SCDM), ventrolateral (SCVL) and caudal (SCC) subareas, ventromedial thalamic area (VM), ventral hypothalamic area (VH), and Edinger-Westphal nucleus (EW-N)

\begin{tabular}{|c|c|c|c|c|c|c|c|c|}
\hline \multicolumn{3}{|c|}{ Brain structure } & \multirow{2}{*}{$\begin{array}{l}\text { Fos } \\
7.2 \pm 1.6^{*}\end{array}$} & \multirow{2}{*}{$\begin{array}{l}\mathrm{CRF} \\
8.2 \pm 1.6^{*}\end{array}$} & \multirow{2}{*}{$\begin{array}{l}\text { Ucn } 1 \\
28.6 \pm 4.4^{*}\end{array}$} & \multirow{2}{*}{$\begin{array}{l}\text { CART } \\
13.0 \pm 3.2^{*}\end{array}$} & \multirow{2}{*}{$\begin{array}{l}\text { ENK } \\
25.6 \pm 5.2^{* *}\end{array}$} & \multirow{2}{*}{$\frac{\text { NPY }}{a}$} \\
\hline$\overline{\mathrm{Mg}}$ & $\mathrm{MgV}$ & Control & & & & & & \\
\hline & & Starved & $2.2 \pm 0.8$ & $13.8 \pm 1.8$ & $16 \pm 2.3$ & $1.8 \pm 0.8$ & $7 \pm 1.6$ & $\mathrm{a}$ \\
\hline & $\mathrm{MgM}$ & Control & $14.2 \pm 2.7^{*}$ & $2.2 \pm 0.3^{* *}$ & $17.8 \pm 1.1$ & $18.6 \pm 7.6^{* *}$ & $43.6 \pm 7.2^{* *}$ & $\mathrm{a}$ \\
\hline & $\mathrm{MgD}$ & Control & $7.2 \pm 1.7$ & $\mathrm{a}$ & $\mathrm{a}$ & $\mathrm{a}$ & $50.4 \pm 2.8^{* *}$ & $\mathrm{a}$ \\
\hline & & Starved & $3.6 \pm 1.1$ & $\mathrm{a}$ & $\mathrm{a}$ & $\mathrm{a}$ & $16.6 \pm 5.4$ & $\mathrm{a}$ \\
\hline \multicolumn{2}{|l|}{$\mathrm{Mg}$ total } & Control & $28.6 \pm 5.5^{*}$ & $10.4 \pm 1.8^{*}$ & $46.4 \pm 4.4$ & $31.6 \pm 7.0^{* *}$ & $119.6 \pm 10.6^{*}$ & $\mathrm{a}$ \\
\hline \multirow[t]{6}{*}{$\mathrm{SC}$} & SCDM & Control & $18.4 \pm 5.3$ & $17 \pm 1.7$ & $\mathrm{a}$ & $78.8 \pm 3.4$ & $22.0 \pm 3.6$ & $2.8 \pm 1.3^{*}$ \\
\hline & & Starved & $25.2 \pm 10.5$ & $17 \pm 3.3$ & $\mathrm{a}$ & $65.2 \pm 8.3$ & $22.2 \pm 2.4$ & $16.6 \pm 4.4$ \\
\hline & SCVL & Control & $13 \pm 5.1$ & $\mathrm{a}$ & $\mathrm{a}$ & $\mathrm{a}$ & $\mathrm{a}$ & $4.8 \pm 2.1$ \\
\hline & & Starved & $22.8 \pm 8.4$ & $\mathrm{a}$ & a & $\mathrm{a}$ & $\mathrm{a}$ & $2.8 \pm 1.2$ \\
\hline & SCC & Control & $5 \pm 1.3$ & $3.2 \pm 0.7$ & $\mathrm{a}$ & $\mathrm{a}$ & $4.2 \pm 2.0$ & $1.6 \pm 0.9$ \\
\hline & & Starved & $7.2 \pm 2.4$ & $3.8 \pm 1.2$ & $\mathrm{a}$ & $\mathrm{a}$ & $8.8 \pm 3.4$ & $6.2 \pm 1.8$ \\
\hline & & Starved & $14.8 \pm 6.0$ & $6.2 \pm 0.7$ & $\mathrm{a}$ & $150.2 \pm 24.5$ & $\mathrm{a}$ & $62.6 \pm 6.4$ \\
\hline \multirow[t]{2}{*}{ VH } & & Control & $14.6 \pm 4.8$ & $17.4 \pm 1.6$ & $\mathrm{a}$ & $79.6 \pm 11.1$ & $59.0 \pm 7.3$ & $23.2 \pm 2.9$ \\
\hline & & Starved & $12.8 \pm 4.8$ & $21.0 \pm 2.1$ & $\mathrm{a}$ & $67.4 \pm 7.4$ & $66.5 \pm 11.2$ & $24.1 \pm 3.5$ \\
\hline \multirow[t]{2}{*}{ EW-N } & & Control & $12.8 \pm 5.2$ & $\mathrm{a}$ & $29.2 \pm 1.2$ & $47.8 \pm 5.0^{*}$ & $\mathrm{a}$ & $\mathrm{a}$ \\
\hline & & Starved & $9.6 \pm 3.9$ & a & $34.7 \pm 5.2$ & $27.6 \pm 3.6$ & $\mathrm{a}$ & a \\
\hline \multirow[t]{2}{*}{ NL } & & Control & $\mathrm{a}$ & $\mathrm{nm}$ & $1.1 \pm 0.2$ & $82.0 \pm 6.3^{*}$ & $48.6 \pm 4.2$ & $\mathrm{a}$ \\
\hline & & Starved & $\mathrm{a}$ & $\mathrm{nm}$ & $1.7 \pm 0.8$ & $63.5 \pm 1.2$ & $55.8 \pm 9.0$ & $\mathrm{a}$ \\
\hline \multirow[t]{2}{*}{$\mathrm{Me}$} & & Control & $\mathrm{nm}$ & $51.1 \pm 1.6$ & $\mathrm{~nm}$ & $\mathrm{~nm}$ & $\mathrm{~nm}$ & $\mathrm{~nm}$ \\
\hline & & Starved & $\mathrm{nm}$ & $49.0 \pm 5.1$ & $\mathrm{~nm}$ & $\mathrm{~nm}$ & $\mathrm{~nm}$ & $\mathrm{~nm}$ \\
\hline
\end{tabular}

Intensity of immunostaining of fibres positive to Ucn1, CART and ENK in the neural lobe (NL) of the pituitary gland and in the median eminence (Me) is measured as specific signal density (SSD). Values are expressed as mean per group \pm standard error of the mean (SEM). Asterisks indicate statistically significant difference between control and starved group $\left({ }^{*} P<0.05\right.$ and $\left.{ }^{* *} P<0.001\right) . n=5$ animals per group. a, absent; nm, not measured. 

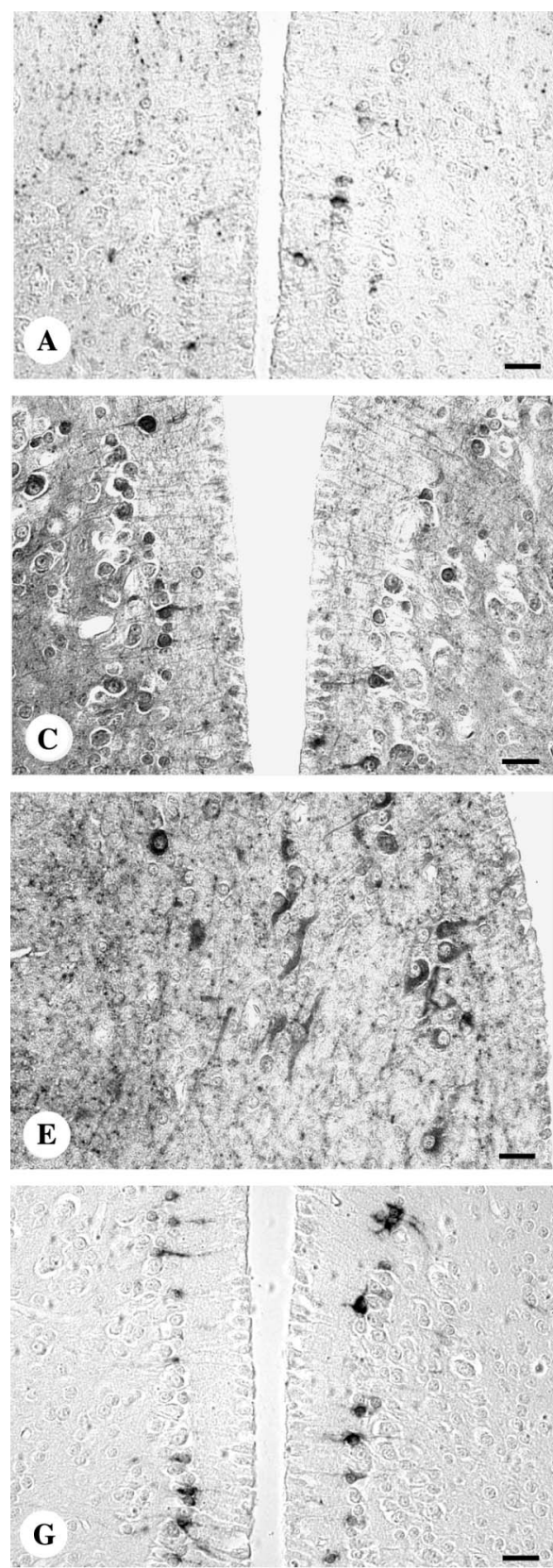

Fig. 2. Coronal sections at different levels of the $\mathrm{Mg}$, in a representative control (left) and starved (right) animal, immunopositive for (A,B) $\mathrm{CRF}$ (in $\mathrm{MgV}$ ), (C,D) CART (in MgM), (E,F) ENK (in MgM), and (G,H) Ucn1 (in MgV). Scale bar $=20 \mu \mathrm{m}$.

fibres are very scarce in the neural lobe (cf. Roubos et al., 2005), their staining could not be reliably assessed. In contrast, the median eminence contains many CRF-containing fibres, enabling measurement of the SSD of CRF-ir in this brain structure. However, no difference was observed between control and starved animals (Table 1).

The other brain structures quantified show less extensive reactions to the starvation stimulus than the Mg. NPY-ir neurones occur in three sub-areas of the SC, viz. in the dorsomedial, the ventrolateral and the caudal area. The dorsomedial area shows 5.9 times more NPY-positive neurones in starved than in control animals $(P<0.05$; Figs. 3C and $\mathrm{D})$; the other two areas do not reveal a difference between the experimental groups. Furthermore, starved
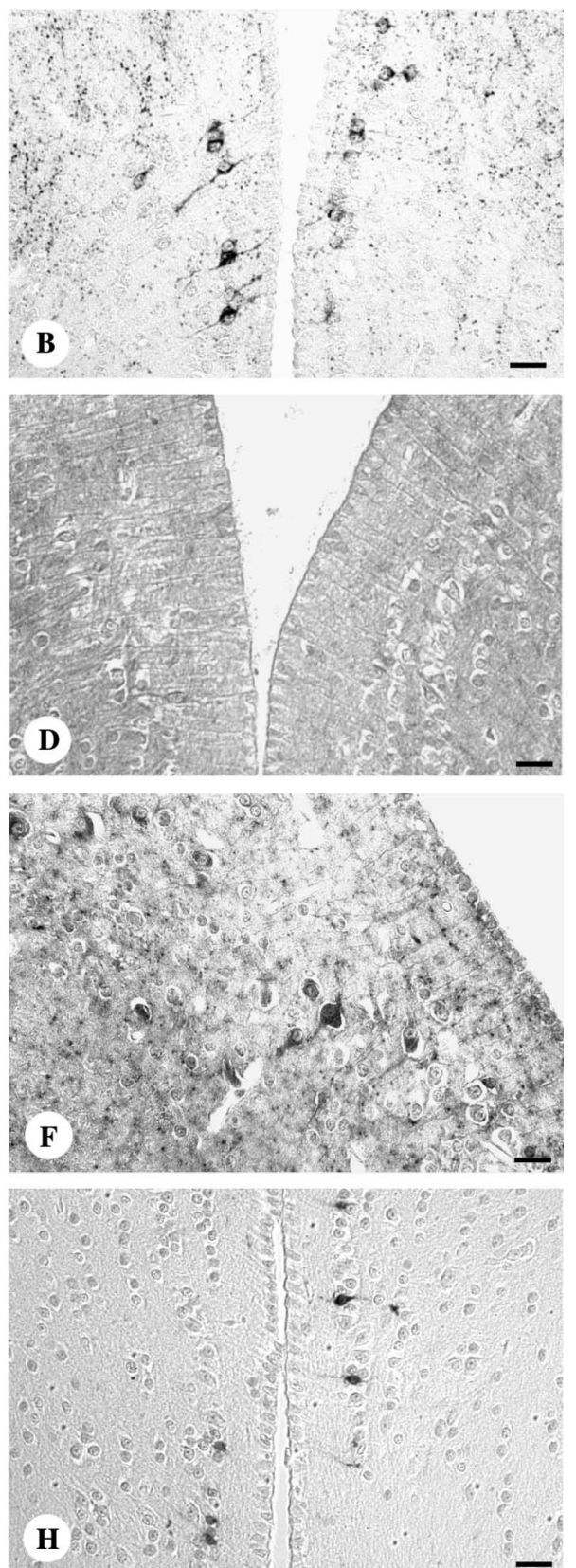

animals reveal a lower number of NPY-positive neurones in the VM $(-33.6 \% ; P<0.05$; Figs. $3 \mathrm{E}$ and $\mathrm{F})$, whereas CART-positive neurones are less numerous in the EdingerWestphal nucleus $(-42.2 ; P<0.05$; Figs. $3 \mathrm{G}$ and $\mathrm{H}$; Table 1). In the VH no effect of starvation on any of the neuropeptide-containing neurones was observed.

\subsection{Cell size and stainability}

In general, the shape and size of neurones in the brain of $X$. laevis are rather variable, round, ovoid, and pleomorph perikarya of different sizes being intermingled within a given brain structure. Moreover, variability was seen in the degree of immunoreactivity among such neurones. Pilot 

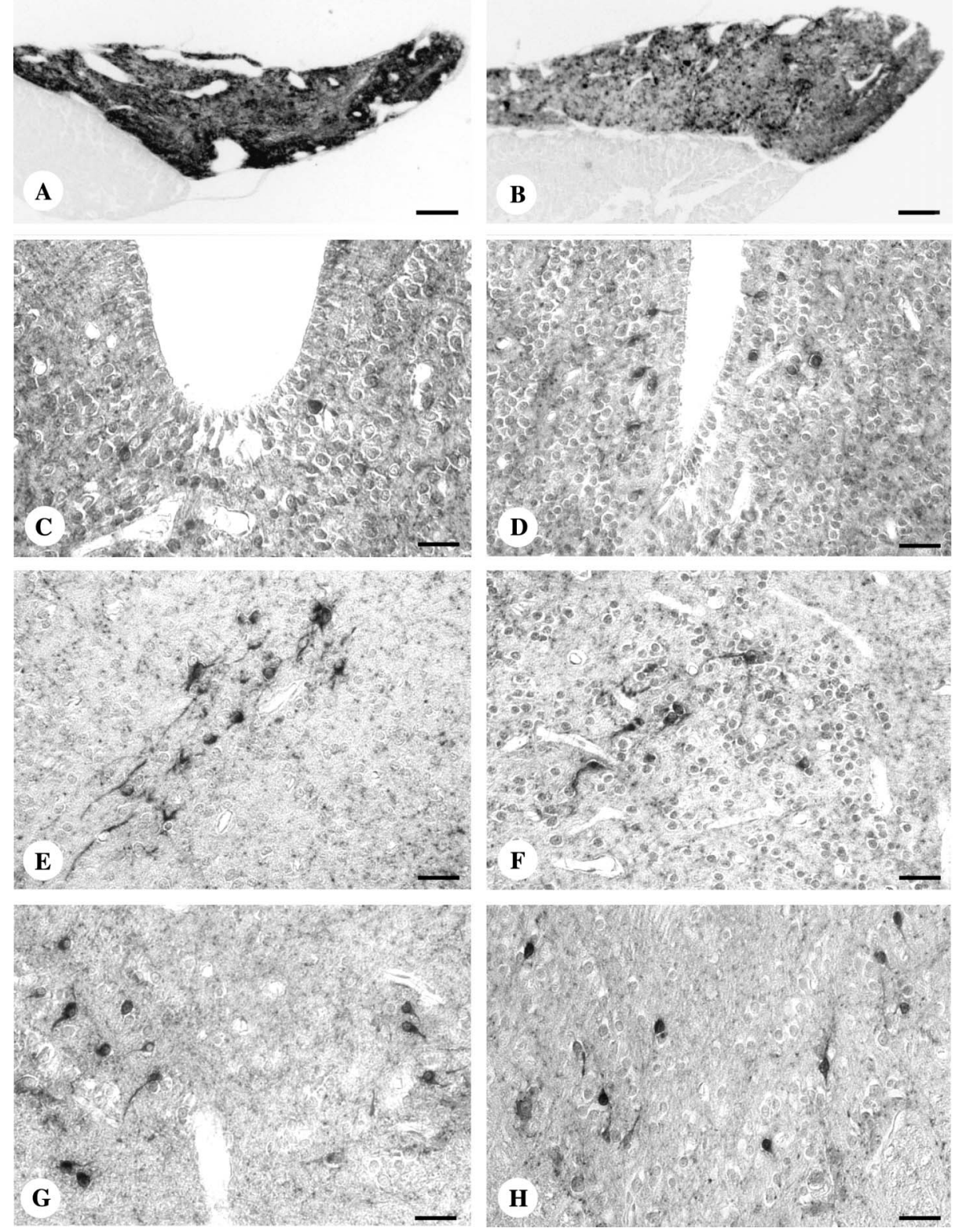

Fig. 3. Coronal sections of a representative control (left) and starved (right) animal at the level of (A,B) the neural lobe of the pituitary gland, showing CART-ir fibers, (C,D) dorsomedial part of the suprachiasmatic nucleus with NPY-ir neurones, (E,F) ventromedial thalamic area with NPY-ir cells, and $(\mathrm{G}, \mathrm{H})$ Edinger-Westphal nucleus with CART-ir neurones. Scale bar $=20 \mu \mathrm{m}$.

studies have shown before that, because of this variability, no accurate measurements can be made to show a possible effect of starvation on shape, size, and intensity of immunostaining of individual perikarya. Nevertheless, in one case quantitative assessment of cell size could be carried out reliably, as the difference between controls and starved animals turned out to be very considerable: in the three subareas of the $\mathrm{Mg}$ of starved animals ENK-ir neurones appeared to be clearly smaller than their counterparts in control animals (MgV: $-17.0 \%, P<0.05$; MgM: $-22.4 \%, P<0.001$; MgD: $-26.0 \%, P<0.001)$. Also, these neurones were clearly less intensily stained (Fig. 4).

\section{Discussion}

\subsection{Methodological considerations}

In this study, we have followed a combined physiological (starvation paradigm) and quantitative immunocytochemical (neuropeptide and Fos presence) approach to test the hypothesis that CRF and Ucn 1 peptides in the Mg of the brain of $X$. laevis are involved in the control of feedingrelated processes. Starvation is a common tool to investigate the role of brain peptides in such processes as it drastically affects the dynamics of feeding and gastrointestinal 


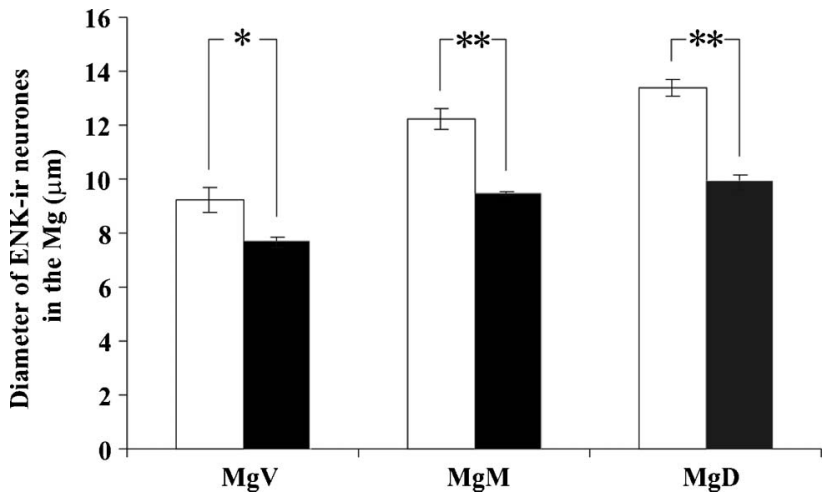

Fig. 4. Effect of starvation on mean diameter of neuronal perikarya profiles immunoreactive to ENK in the $\mathrm{Mg}$ subareas, $\mathrm{MgV}, \mathrm{MgM}$, and $\mathrm{MgD}$, in (white bars) control animals and (black bars) starved animals. Values are expressed as means \pm standard error of the mean (SEM). Asterisks indicate significant difference between control and starved animals $\left({ }^{*} P<0.05,{ }^{* *} P<0.001\right)$.

activity (e.g., Bertile et al., 2003; Chaillou et al., 2000), but it may have the disadvantage of evoking strong side-effects when it inhibits general metabolism and activates the hypothalamic-pituitary-adrenal stress axis, especially after a prolonged period of food deprivation (Hervant et al., 2001; Hervant and Renault, 2002). However, since Crespi et al. (2004) showed that in X. laevis plasma, corticosterone levels are not increased after one month of food deprivation and since $X$. laevis is well capable to survive long periods of drastically reduced food supply, up to 18 months (Merkle and Hanke, 1988), such side-effects may not be expected in our study, making our starvation stimulus of 16 weeks a specific factor acting on the feeding control system rather than being a factor activating the stress axis. Moreover, the effects of starvation on the presence of various neurochemical messengers and Fos are distinct and specific for a given messenger and brain structure, which would not have been expected when the starvation stimulus would have led to general inhibition of neuronal secretory activity. Moreover, some of the effects observed, like changes in NPY-ir in the $\mathrm{SC}$ and CART-ir in the EW-N have never been shown to be related to chronic stress effects (CART in the EW-N only changes during acute stress in mammals; Kozicz, 2003). Therefore, the effects on brain structures observed in the present study seem to be related to starvation-induced changes in neuronal control mechanisms of feeding-related events, rather than to stress- and/or metabolism-related processes.

Quantitative immunocytochemistry and in situ hybridization comprise the best techniques to obtain information about the secretory activity of individual neurones and their specific messengers, in intact brain tissue. Our approach to count the number of immunopositive cell profiles yields an impression about the amount of neuropeptide present in the brain structure. Obviously, this amount of stored messenger is not a direct measure for the cell's secretory activity, as according to the 'bath tube' principle, this amount depends on the balance between production and turnover and, in case of the messengers, also of the rate of axonal transport (e.g., Siegel, 1999). However, changes in the amount of stored stainable material indicate that this balance is changed and, therefore, such changes are good indicators that the brain structure in question is responding to the stimulus, in our case to starvation. Moreover, staining of a neuron with the Fos method is well-accepted to be a reliable indicator of neuronal activity, so that the Fos method in combination with immunoreactions to the various messengers provides a meaningful picture of the structures responding to the stimulus. In $X$. laevis the expression of Fos was demonstrated previously as being prolonged and apparently related to events like stimulated neuronal plasticity and chronic stimulation of secretory activity (Ubink et al., 1997).

\subsection{Starvation and the magnocellular nucleus}

Of the five brain structures investigated in detail, the $\mathrm{Mg}$ shows the strongest difference between starved and control animals as to the various immunocytochemical parameters. On the basis of the assumptions made above with regard to the significance of the parameters for neuronal activity, we conclude that especially the $\mathrm{MgV}$ and the $\mathrm{MgM}$ are extensively responding to the starvation stimulus by showing changed dynamics in storage, and hence, production and/or secretion of CRF, Ucn1, CART, and ENK. The significance of the differential responses of the three subareas of the $\mathrm{Mg}$ awaits their detailed functional elucidation. In any case, these responses are specific for the $\mathrm{Mg}$ because no other structure shows a decrease in Fos expression in response to starvation.

Since the $\mathrm{Mg}$ is a well-known centre of CRF production, it is tempting to relate the decreased Fos activity to a decreased activity of CRF-producing neurones. Such a decrease would be in accordance with and extend the observation by Crespi et al. (2004) that long-term starvation of $X$. laevis leads to a decrease in CRF mRNA in the preoptic/ optic tectum/mid-posterior hypothalamus, as this region contains the Mg. However, to date it is not possible to relate the decreased amount of Fos in the Mg to CRF or to any other of the messengers investigated. This will only be possible by colocalization studies at the cellular level, which are difficult to perform because antisera available for immunodouble stainings are mainly raised in the same animal (rabbit) and for most peptide mRNAs of interest, specific (Xenopus)in situ probes are not available.

Meanwhile, our data show markedly changed immunoreactivities of the $\mathrm{Mg}$ to the various antisera, which strongly indicates that CRF, CART and/or ENK in the $\mathrm{Mg}$, and particularly in the $\mathrm{MgV}$ and the $\mathrm{MgM}$, play a role in feeding in $X$. laevis. A main role of the $\mathrm{Mg}$ in amphibians in feeding-related events fits with the notion that the $\mathrm{Mg}$ homologue in mammals, the PVN, may control feeding as well (Krahn et al., 1988; Wang et al., 2001). Our results furthermore indicate for the first time a role in feeding-related processes in amphibians of CART and ENK, peptides 
shown before to be involved in this process in mammals (Glass et al., 1999; Henry et al., 2001; Kristensen et al., 1998). As we found a low intensity of CART-staining in the pituitary neural lobe after starvation, it may be that CART is released into the general circulation to act on peripheral targets, as is the case in mammals (Vicentic et al., 2004, 2005). On the other hand, the possibility cannot be ruled out that CART, like many other peptides present in the neural lobe (Roubos et al., 2005; Wang et al., 2005), has a stimulatory effect on the pituitary intermediate lobe, as it has in mammals (Baranowska et al., 2004; Kuriyama et al., 2004), regulating (in addition to feeding) the activity of the melanotrope cells. As to ENK, our observation of a decreased stainability and decreased cell size underlines the notion that these cells change, and probably reduce, their activity during starvation. The possibility that ENK plays a role in starvation-induced adaptive processes in amphibians deserves further attention.

Although statistically an effect of starvation on the number of Ucn1-ir neurones in the total Mg could not be demonstrated, such an effect became visible when the subareas of the nucleus were considered, revealing a much lower number of Ucn1-positive neurones in the MgV. This result supports our hypothesis that $\mathrm{Ucn} 1$ in the $\mathrm{Mg}$, and more particularly in the $\mathrm{MgV}$, is involved in the control of food intake in $X$. laevis. This conclusion extends the finding that central Ucn1 administration in $X$. laevis suppresses food intake in a dose-dependent manner (Boorse et al., 2005) and is in line with the situation in mammals, where food deprivation induces a down-regulation of Ucn1-ir neurones in the PVN (Hara et al., 1997).

\subsection{Starvation and other brain centres}

Besides having an effect on the $\mathrm{Mg}$, starvation also affects three other brain structures, albeit in different ways. Crespi et al. (2004) have shown that food deprivation leads to changes in the amount of NPY mRNA in the Xenopus brain. In the present study, we find two centres that respond to starvation with changed dynamics of NPY as to the number of neurones containing NPY: the SC (more neurones immunoreactive to NPY) and the VM (less neurones immunoreactive to NPY), suggesting changed amounts of NPY stored in these nuclei. Neither nucleus has been shown before to be involved in the regulation of processes related to feeding, neither in mammals nor in amphibians. Therefore, more evidence is needed to conclude that these nuclei would play such a role. In case of the SC this role would be in addition to the control by NPY of melanotrope cell activity in the pituitary pars intermedia. NPY neurones in the dorsomedial part of this nucleus are supposed to inhibit the so-called SMINs (suprachiasmatic melanotrope cell-inhibitory neurones) in the ventrolateral part, which, also by releasing NPY, inhibit the melanotrope cells. Further research is needed to see if the neurones reacting to the starvation stimulus are identical with these dorsomedial inhibitory neurones (Kramer et al., 2001; Scheenen et al.,
1995; Tuinhof et al., 1994). Similarly, it would be of interest to determine if the neurones in the thalamus that inhibit tectal pathways controlling prey-catching behavior (Carr, 2005) are identical to the NPY-neurones presently studied in the VM.

No differences between starved and control animals were found in the VH. The VH is considered to be the homologue of the arcuate nucleus in mammals (Tuinhof et al., 1998) where it is supposed to play an important role in the control of food intake (Schwartz et al., 2000). The present study does not support such a role of the $\mathrm{VH}$ in $X$. laevis but does not exclude it either as our paradigm probably covers only a minor part of all activities of this extensive nucleus.

Finally, we have found a lower number of CART-ir cells in the Edinger-Westphal nucleus of starved animals. This oculomotor nucleus has recently gained much attention as it is the main site of Ucn 1, the member of the CRF peptide family that may play important roles in various types of stress adaptation in rodents (Kórösi et al., 2005; Kozicz et al., 2004). The present study represents the first report of an effect of starvation on this nucleus. The fact that in this nucleus no effect on Ucn1-containing neurones is seen, is in line with the assumption reached above that 16 weeks of starvation is not a stressor for $X$. laevis. Meanwhile, the possible role of Ucn1 in the EW-N of amphibians in stress adaptation needs to be established (cf. in mammals: Kórösi et al., 2005; Kozicz et al., 2004). The change in CART neurones, may indicate a role of this peptide in feeding, but more research on the role of this peptide to substantiate this suggestion and to test a possible relationship between CART and Ucn1 activities in this nucleus is needed.

\subsection{Conclusions}

We conclude that starvation has profound effects on the neurochemical contents of the three subareas of the $\mathrm{Mg}$, especially the $\mathrm{MgV}$ and $\mathrm{MgM}$, of $X$. laevis, indicating a role of CRF and Ucn1 and possibly of CART and ENK in the regulation of feeding activity. Moreover, we have found indications that in amphibians CART, ENK, and NPY may be involved in the regulation of feeding-related processes, acting in distinct brain centres.

\section{Acknowledgments}

We gratefully acknowledge the gifts of synthetic peptides and antisera by Drs R. Denver (Ann Arbor, NI, USA; CRF, Ucn1, Ucn3, and anti-CRF), Dr. W.W. Vale (La Jolla, CA, USA; anti-Ucn1), M.A. Verhage (Amsterdam, The Netherlands; anti-ENK), H. Vaudry (Rouen, France; anti-NPY), and L. Thim and J.T. Clausen (Novo Nordisc A/S, Bagverd, Denmark; CART and anti-CART, respectively). The authors are grateful to Mrs F.J. KuijpersKwant for technical assistance and to Mr R.J.C. Engels for animal care. 


\section{References}

Baigent, S.M., Lowry, P.J., 2000. mRNA expression profiles for corticotrophin-releasing factor (CRF), urocortin, $\mathrm{CRF}$ receptors and CRF-binding protein in peripheral rat tissues. J. Mol. Endocrinol. 25, 43-52.

Baranowska, B., Wolinka-Witort, E., Martynska, L., Chmielonwska, M., Baranowska-Bik, A., 2004. Effects of cocaine-amphetamine regulated transcript (CART) on hormone release. Regul. Pept. 15, 55-59.

Bertile, F., Oudart, H., Criscuolo, F., Maho, Y.L., Raclot, T., 2003. Hypothalamic gene expression in long-term fasted rats: relationship with body fat. Biochem. Biophys. Res. Commun. 303, 1106-1113.

Bittencourt, J.C., Vaughan, J., Arias, C., Rissman, R.A., Vale, W.W., Sawchenko, P.E., 1999. Urocortin expression in rat brain: evidence against a pervasive relationship of urocortin-containing projections with targets bearing type 2 CRF receptors. J. Comp. Neurol. 415, 285-312.

Bliss, C.J., 1967. Statistics in Biology, vol. 1. McGraw-Hill, New York.

Boorse, G.C., Denver, R.J., 2004. Expression and hypophysiotropic actions of corticotropin-releasing factor in Xenopus laevis. Gen. Comp. Endocrinol. 137, 272-282.

Boorse, G.C., Crespi, E.J., Dautzenberg, F.M., Denver, R.J., 2005. Urocortins of the South African clawed frog, Xenopus laevis: conservation of structure and function in tetrapod evolution. Endocrinology 11, 48514860.

Carr, J.A., 2005. Novel effects of CRF on visuomotor behavior and autonomic function in anuran amphibians. Gen. Comp. Endocrinol. (Epub, ahead of print)

Calle, M., Corstens, G.J.H., Wang, L., Kozicz, T., Denver, R.J., Barendregt, H.P., Roubos, E.W., 2005a. Evidence that urocortin I acts as a neurohormone to stimulate alpha-MSH release in the toad Xenopus laevis. Brain Res. 1040, 14-28.

Calle, M., Claassen, I.E.W.M., Veening, J.G., Kozicz, T., Roubos, E.W., Barendregt, H.P., 2005b. Opioid Peptides, CRF, and urocortin in cerebrospinal fluid-contacting neurones in Xenopus laevis. In: Vaudry, H., Roubos, E.W., Schoofs, L., Flik, G., Larhammar, D. (Eds). Trends in Comparative Endocrinology and Neurobiology. Ann. N. Y. Acad. Sci. 1040, 249-252.

Chaillou, E., Baumont, R., Tramu, G., Tillet, Y., 2000. Effect of feeding on fos protein expression in sheep hypothalamus with special reference to the supraoptic and paraventricular nuclei: an immunohistochemical study. Eur. J. Neurosci. 12, 4515-4524.

Crespi, E.J., Vaudry, H., Denver, R.J., 2004. Roles of corticotropin-releasing factor, neuropeptide $\mathrm{Y}$ and corticosterone in the regulation of food intake in Xenopus laevis. J. Neuroendocrinol. 16, 279-288.

Donkelaar, H.J. ten, 1998. Anurans. In: Nieuwenhuys, R., ten Donkelaar, H.J., Nicholson, C. (Eds.), The Central Nervous System of Vertebrates, vol. 2. Springer.

Douglass, J., McKinzie, A.A., Couceyro, P., 1995. PCR differential display identifies a rat brain mRNA that is transcriptionally regulated by cocaine and amphetamine. J. Neurosci. 15, 2471-2481.

Glass, M.J., Billington, C.J., Levine, A.S., 1999. Opioids and food intake: distributed functional neural pathways? Neuropeptides 33, 360-368.

Gosnell, B.A., Lipton, J.M., 1986. Opioid peptide effects on feeding in rabbits. Peptides 7, 745-747.

Hara, Y., Ueta, Y., Isse, T., Kabashima, N., Shibuya, I., Hattori, Y., Yamashita, H., 1997. Increase of urocortin-like immunoreactivity in the rat supraoptic nucleus after dehydratation but not food deprivation. Neurosci. Lett. 229, 65-68.

Heinrichs, S.C., Richard, D., 1999. The role of corticotropin-releasing factor and urocortin in the modulation of ingestive behavior. Neuropeptides $33,350-359$

Henry, B.A., Rao, A., Ikenasio, B.A., Mountjoy, K.G., Tilbrook, A.J., Clarke, I.J., 2001. Differential expression of cocaine- and amphetamine-regulated transcript and agouti related-protein in chronically food-restricted sheep. Brain Res. 918, 40-50.

Hervant, F., Mathieu, J., Durand, J., 2001. Behavioural, physiological and metabolic responses to long-term starvation and refeeding in a blind cave-dwelling (Proteus anguinus) and a surface-dwelling (Euproctus asper) salamander. J. Exp. Biol. 204, 269-281.
Hervant, F., Renault, D., 2002. Long-term fasting and realimentation in hypogean and epigean isopods: a proposed adaptive strategy for groundwater organisms. J. Exp. Biol. 205, 2079-2087.

Jenks, B.G., Ouwens, D.T., Coolen, M.W., Roubos, E.W., Martens, G.J.M., 2002. Demonstration of postsynaptic receptor plasticity in an amphibian neuroendocrine interface. J. Neuroendocrinol. 14, 843-845.

Johansen, J.E., Broberger, C., Lavebratt, C., Johansson, C., Kuhar, M.J., Hokfelt, T., Schalling, M., 2000. Hypothalamic CART and serum leptin levels are reduced in the anorectic (anx/anx) mouse. Brain Res. Mol. $84,97-105$.

Jones, D.N.C., Kortekaas, R., Slade, P.D., Middlemiss, D.N., Hagan, J.J., 1998. The behavioural effects of corticotropin-releasing factor-related peptides in rats. Psychopharmacology 138, 124-132.

Kórösi, A., Schotanus, S., Olivier, B., Roubos, E.W., Kozicz, T., 2005. Chronic ether stress-induced response of urocortin 1 neurons in the edinger-westphal nucleus in the mouse. Brain Res. 1046, 172-179.

Koylu, E.O., Couceyro, P.R., Lambert, P.D., Ling, N.C., DeSouza, E.B., Kuhar, M.J., 1997. Immunohistochemical localization of novel CART peptides in rat hypothalamus, pituitary and adrenal gland. J. Neuroendocrinol. 9, 823-833.

Kozicz, T., Yanaihara, H., Arimura, A., 1998. Distribution of urocortinlike immunoreactivity in the central nervous system of the rat. J. Comp. Neurol. 391, 1-10.

Kozicz, T., Arimura, A., Maderdrut, J.L., Lázár, G., 2002. Distribution of urocortin-like immunoreactivity in the central nervous system of the frog Rana esculenta. J. Comp. Neurol. 453, 185-198.

Kozicz, T., 2003. Neurons colocalizing urocortin and cocaine and amphetamine-regulated transcript immunoreactivities are induced by acute lipopolysaccharide stress in the Eddinger-Westphal nucleus in the rat. Neuroscience 116, 315-320.

Kozicz, T., Kórösi, A., Korsman, C., Tilburg-Ouwens, D., Groenink, L., Veening, J.G., Gugten, J., van der Roubos, E.W., Olivier, B., 2004. Urocortin expression in the Edinger-Westphal nucleus is down-regulated in transgenic mice over-expressing neuronal corticotropin-releasing factor. Neuroscience 123, 589-594.

Krahn, D.D., Gosnell, B.A., Levine, A.S., Morley, J.E., 1988. Behavioral effects of corticotropin-releasing factor: localization and characterization of central effects. Brain Res. 443, 63-69.

Kramer, B.M., Welting, J., Berghs, C.A.F.M., Jenks, B.G., Roubos, E.W., 2001. Functional organization of the suprachiasmatic nucleus of Xenopus laevis in relation to background adaptation. J. Comp. Neurol. 432, 346-355.

Kristensen, P., Judge, M.E., Thim, L., Ribel, U., Christjansen, K.N., Wulff, B.S., Clausen, J.T., Jensen, P.B., Madsen, O.D., Vrang, N., Larsen, P.J., Hastrup, S., 1998. Hypothalamic CART is a new anorectic peptide regulated by leptin. Nature 393, 72-76.

Kuhar, M.J., Dall, V.S., 1999. CART peptides: novel addiction- and feeding-related neuropeptides. Trends Neurosci. 22, 316-320.

Kuriyama, G., Takekoshi, S., Tojo, K., Nakai, Y., Kuhar, M.J., Osamura, R.Y., 2004. Cocaine-and amphetamine-regulated transcript peptide in the rat anterior pituitary gland is localized in gonadotrophs and suppresses prolactin secretion. Endocrinology 145, 2542-2550.

Lázár, G., Calle, M., Roubos, E.W., Kozicz, T., 2004. Immunohistochemical localization of cocaine- and amphetamine-regulated transcript peptide in the central nervous system of the frog Rana esculenta. J. Comp. Neurol. 477, 324-339.

Merchenthaler, I., Maderdrut, J.L., Lázár, G., Gulyas, J., Petrusz, P., 1987. Immunocytochemical analysis of proenkephalin-derived peptides in the amphibian hypothalamus and optic tectum. Brain res. 416, 219 227.

Merkle, S., Hanke, W., 1988. Long-term starvation in Xenopus laevis Daudin-II. Effects on several organs. Comp. Biochem. Physiol. 90, 491-495.

Momose, K., Inui, A., Asakawa, A., Ueno, N., Nakajima, M., Fujimiya, M., Kasuga, M., 1999. Intracerebroventricularly administered corticotropin-releasing factor inhibits food intake and produces anxiety-like behaviour at very low doses in mice. Diabetes Obes. Metab. 1, 281-284.

Parkes, D.G., Weisinger, R.S., May, C.N., 2001. Cardiovascular actions of CRH and urocortin: an update. Peptides 22, 821-827. 
Roubos, E.W., 1997. Background adaptation by Xenopus laevis: a model for studying neuronal information processing in the pituitary pars intermedia. Comp. Biochem. Physiol. 118, 533-550.

Roubos, E.W., Scheenen, W.J.J.M., Jenks, B.G., 2005. Neuronal, neurohormonal, and autocrine control of Xenopus melanotrope cell activity. Ann. NY Acad. Sci. 1040, 172-183.

Scheenen, W.J.J.M., Yntema, H.G., Willems, P.H.G.M., Roubos, E.W., Lieste, J.R., Jenks, B.G., 1995. Neuropeptide Y inhibits $\mathrm{Ca}^{2+}$ oscillations, cyclic AMP, and secretion in melanotrope cells of Xenopus laevis via a Y1 receptor. Peptides 16, 889-895.

Schwartz, M.W., Woods, S.C., Porte Jr., D., Seeley, R.J., Baskin, D.G., 2000. Central nervous system control of food intake. Nature 404, 661671.

Shapiro, H.H., Wilk, M.B., 1965. An analysis of variance test for normality. Biometrika 52, 591-611.

Shi, S.R., Chaiwun, B., Young, L., Cote, R.J., Taylor, C.R., 1993. Antigen retrieval technique utilizing citrate buffer or urea solution for immunohistochemical demonstration of androgen receptor in formalin-fixed paraffin sections. J. Histochem. Cytochem. 41, 1599-1604.

Siegel, G.J., 1999. Neuropeptide functions and regulations. In: Siegel, G.J., Agranoff, B.W., Albers, R.W., Fisher, S.K., Uhler, M.D. (Eds.), sixth ed.. Basic Neurochemistry: Molecular, Cellular and Medical Aspects, vol. II. Lippincott Williams \& Wilkins.

Skelton, K.H., Owens, M.J., Nemeroff, C.B., 2000. The neurobiology of urocortin. Regul. Pept. 93, 85-92.

Spina, M., Merlo-Pich, E., Chan, R.K., Basso, A.M., Rivier, J., Vale, W.W., Koob, G.F., 1996. Appetite-suppressing effects of urocortin, a CRFrelated neuropeptide. Science 273, 1561-1564.

Stanley, B.G., Leibowitz, S.F., 1985. Neuropeptide Y injected in the paraventricular hypothalamus: a powerful stimulant of feeding behavior. Proc. Natl. Acad. Sci. USA 82, 3940-3943.

Tsigos, C., Chrousos, G.P., 2002. Hypothalamic-pituitary-adrenal axis, neuroendocrine factors and stress. J. Psychosom. Res. 53, 865-871.

Tuinhof, R., Gonzalez, A., Smeets, W.J., Roubos, E.W., 1994. Neuropeptide $\mathrm{Y}$ in the developing and adult brain of the south african clawed toad Xenopus laevis. J. Chem. Neuroanat. 7, 271-283.

Tuinhof, R., Ubink, R., Tanaka, S., Atzori, C., van Strien, F.J.C., Roubos, E.W., 1998. Distribution of pro-opiomelanocortin and its peptides end products in the brain and hypophysis of the aquatic toad, Xenopus laevis. Cell Tissue Res. 292, 251-265.

Ubink, R., Jenks, B.G., Roubos, E.W., 1997. Physiologically induced fos expression in the hypothalamo-hypophyseal system of Xenopus laevis. Neuroendocrinology 65, 413-422.

Vale, W.W., Spiess, J., Rivier, C., Rivier, J., 1981. Characterization of a 41residue ovine hypothalamic peptide that stimulates secretion of corticotropin and beta-endorphin. Science 213, 1394-1397.

Vaughan, J., Donaldson, C., Bittencourt, J., Perrin, M.H., Lewis, K., Sutton, S., Chan, R., Turnbull, A.V., Lovejoy, D., Rivier, C., 1995. Urocortin, a mammalian neuropeptide related to fish urotensin I and to corticotropin-releasing factor. Nature 378, 287-292.

Verburg-Van Kemenade, B.M., Jenks, B.G., Cruijsen, P.M., Dings, A., Tonon, M.C., Vaudry, H., 1987. Regulation of MSH release from the neurointermediate lobe of Xenopus laevis by CRF-like peptides. Peptides 8, 1093-1100.

Vicentic, A., Dominguez, G., Hunter, R.G., Philpot, K., Wilson, M., Kuhar, M.J., 2004. Cocaine- and amphetamine-regulated transcript peptide levels in blood exhibit a diurnal rhythm: regulation by glucocorticoids. Endocrinology 145, 4119-4124.

Vicentic, A., Hunter, R.G., Kuhar, M.J., 2005. Effect of corticosterone on CART peptide levels in rat blood. Peptides 26, 531-533.

Vrang, N., Larsen, P.J., Clausen, J.T., Kristensen, P., 1999. Neurochemical characterization of hypothalamic cocaine- amphetamine-regulated transcript neurons. J. Neurosci. 19, 1-8.

Wang, C., Mullet, M.A., Glass, M.J., Billington, C.J., Levine, A.S., Kotz, C.M., 2001. Feeding inhibition by urocortin in the rat hypothalamic paraventricular nucleus. Am. J. Physiol. Regul. Integr. Comp. Physiol. 280, 473-480.

Wang, L., Calle, M., Roubos, E.W., 2005. Brain-derived neurotrophic factor in the hypothalamo-hypophyseal system of Xenopus laevis. In: Vaudry, H., Roubos, E.W., Schoofs, L., Flik, G., Larhammar, D. (Eds). Trends in Comparative Endocrinology and Neurobiology. Ann. N. Y. Acad. Sci. 1040, 512-514.

Yao, M., Westphal, N.J., Denver, R.J., 2004. Distribution and acute stressor-induced activation of corticotrophin-releasing hormone neurones in the central nervous system of Xenopus laevis. J. Neuroendocrinol. 16, 880-893. 